\title{
Ensayo de descalificaciones y maldiciones personales en Celestina y en la traducción catalana de Antoni Bulbena ${ }^{1}$
}

\author{
Xus Ugarte Ballester \\ Universidad de Vic
}

\begin{abstract}
¡Oh maldiziente venenoso! Oye a Salomón do dice que las mujeres y el vino hacen a los hombres renegar.
\end{abstract}

La crítica del siglo Xx ha prestado poca atención a los aspectos cómicos de Celestina; Severin ${ }^{2}$ argumenta que ha estudiado las ironías, aunque sobre todo las trágicas, obviando las cómicas. Albuixech, citando a Severin y a otros autores como Lida de Malkiel, se lamenta asimismo de que los críticos se inhibieran ante el análisis del lenguaje soez y grosero ${ }^{3}$. En el ámbito de las obscenidades verbales, debemos notar que hay sorprendentemente pocas en Celestina, teniendo en cuenta sobre todo que las "obras de burlas» de los cancioneros estaban llenas de lenguaje vulgar. Los chistes picantes en Celestina son de una naturaleza más sutil, aunque abiertamente sexual ${ }^{4}$. La misma estudiosa apuesta por leer el humor desde la perspectiva del público en lugar de la de los personajes (p. 332). Con

1.- Este artículo se inscribe dentro del proyecto del Grupo de Investigación Consolidado (2009 SGR 736) «Textos Literaris Contemporanis: estudi, edició i traducció» de la Universidad de Vic.

2.- Severin, Dorothy. «El humor en La Celestina» en: López Ríos, Santiago (ed) Estudios sobre la "Celestina", Madrid: Istmo. Col. Fundamentos, 2001, p. 327.

3.- Albuixech, Lourdes. «Insultos, pullas y vituperios en Celestina», Celestinesca 25.1-2 (2001): 57-58.

4.- Severin, op.cit. pp. 334-5. Un estudio de Eukene Lacarra versa sobre el humor erótico en Celestina: Lacarra Lanz, Eukene. Sobre los dichos «lascivos y rientes», en: López Ríos, Santiago (ed) (2001) Estudios sobre la "Celestina». Madrid: Istmo, pp. 355- 380 
toda probabilidad, la audiencia y los lectores del siglo XVI consideraban muy graciosas las descalificaciones e insultos que pueblan el discurso de Celestina y de otros textos dramáticos de la época.

Nuestra aportación en este artículo es doble: por una parte, realizar un vaciado exhaustivo de toda la obra de los adjetivos calificativos que menosprecian o atacan al adversario, así como de las frases, que expresan malos deseos y son proferidas en tono amenazador; por otra, cotejar este extenso corpus con el vaciado también completo de la traducción catalana de Celestina (Antoni Bulbena Tosell, 1914), comentando al mismo tiempo las opciones traductológicas del trujamán: léxico, fraseología, arcaísmos, registro, etc.

Albuixech ${ }^{5}$, en su exhaustivo estudio sobre los insultos y vituperios en Celestina, identifica el lenguaje vulgar tan presente en la obra con lo que Bajtin, a partir de su famoso estudio sobre Rabelais, identifica como lenguaje de mercado, popular, grotesco, en definitiva, con la risa y la cultura cómica popular. Ahora bien, Ottavio Di Camillo ${ }^{6}$, discrepa de esta visión bajtiana de Celestina: "Quiero prevenir que la risa en esta obra no tiene nada que ver con la cultura popular y carnavalesca del mundo al revés de Bajtin. La risa no depende más o menos de personajes raros como Gargantúa o Pantagruel, sino del quehacer diario... en La Celestina no es la cultura popular que irrumpe en el mundo oficial, sino la oficial, erudita. Celestina y sus allegados hablan el lenguaje de las aulas universitarias». Aún siendo indiscutible la última frase, lo cierto es que las imprecaciones, juramentos, insultos, etc., pertenecen a una de las divisiones de la cultura cómica popular, al lado de los festejos carnavalescos y otras formas paródicas o rituales del espectáculo ${ }^{7}$. Ciertamente, la vieja alcahueta y los criados simulan hacer gala en ocasiones de un saber y de unos recursos retóricos dignos de doctores; en compensación, las imprecaciones de personajes de alta clase social como Melibea o Calisto pueden ser tan vulgares y punzantes como las de los criados (ver cuadro). Oigamos a Sempronio aleccionando «bibliográficamente» en el acto I a su amo para convencerle de que su mal por Melibea no es único en el mundo: «Oye a Salomón do dice que las mujeres y el vino hacen a los hombres renegar. Conséjate con Séneca y verás en qué las tiene. Escucha al Aristóteles, mira a Bernardo». En el Acto Iv, Melibea inicia sus imprecaciones a Celestina con un "iQuemada seas, alcahueta falsa, hechicera...!» Tampoco tiene desperdicio la original y grotesca descripción de Calisto, en la misma conversación, en forma de punzantes improperios a modo de sarta: «Loco, saltaparedes, fantasma de noche,

5.- Albuixech, op. cit. p. 58.

6.- Di Camillo, Ottavio. «Etica humanística y libertinaje», en: López Ríos, Santiago (ed) Estudios sobre la "Celestina». Madrid: Istmo, 2001, p. 586

7.- Bajtin, Mijail. La cultura popular en la Edad Media y el Renacimiento. El contexto de François Rabelais. Traducción de Julio Forcat y César Conroy. Barcelona: Barral, 1974, p. 10. 
luengo como cigüeña, figura de paramento malpintado». Para Lakarra ${ }^{8}$, la relación entre la ira y el amor nos da la respuesta de semejante actitud, pues la ira era el rasgo más característico de las mujeres libidinosas y/o enamoradas.

De hecho, Elicia, en el primer acto, expresa sus celos vengativos para con Sempronio de la misma forma hiperbólica y salida de tono. El destinatario de las maldiciones y la testigo, Celestina, quitan importancia a la furia desatada de la prostituta, tomando a broma sus insultos. En opinión de Albuixech ${ }^{9}$, este lenguaje abusivo forma parte del mismo juego amoroso, además de constituir algún resabio de pullas, un intercambio de malos deseos frecuente en el siglo XVI, según atestiguan diversos textos dramáticos de esta época. Es interesante señalar, sin embargo, que los personajes de la alta clase social dirigen sin ambages los insultos a sus subordinados, a menudo de forma gratuita y arbitraria; en cambio, criados y prostitutas sólo pueden ejercer la violencia verbal contra sus iguales o en un aparte.

De la distinción entre los insultos, pullas y vituperios con una función a menudo vejatoria y en ocasiones humorística, se ocupa holgadamente la autora mencionada. Por esta razón, y a pesar de lo interesante que resulta desde el punto de vista del lector de cribar los improperios ofensivos de los humorísticos, en este artículo nos centraremos en la recepción al catalán de semejante lenguaje.

\section{La traducción de Antoni Bulbena}

La primera y única versión de Celestina al catalán cumplirá en breve su primer centenario. El bibliógrafo, gramático y prolífico traductor Antoni Bulbena i Tosell la trasladó a la lengua catalana en 1914. De las características de esta traducción, del esbozo biográfico de Bulbena y de sus criterios paremiológicos, así como de la relación de todos los refranes bulbenísticos cotejados con los originales, nos ocupamos en esta misma revista en el número $27^{10}$. Nuestro propósito en el presente artículo es visibilizar la opción traductológica de la versión catalana a partir del corpus completo de insultos y vituperios de Celestina, que agrupa tanto adjetivos como frases

8.- Lakarra, Eukene. «La ira de Melibea a la luz de la filosofía moral», en Beltrán, Rafael y Canet, José Luis (eds), Cinco siglos de "Celestina». Valencia: Universitat de València, 1997, pp. 107-120.

\section{9.- Op. cit. pp. 60-61.}

10.- Ugarte Ballester, Xus. "La traducción catalana de Celestina», Celestinesca 27 (2003): 165210. Véase también Ugarte Ballester, Xus. "Antoni Bulbena, traductor prolífico de clásicos castellanos al catalán: algunas traducciones inéditas», en: Vega Cernuda, Miguel Ángel (ed) La traducción de los clásicos: problemas y perspectivas. Madrid: Instituto Universitario de Lenguas Modernas y Traductores, 2005, pp. 27-38. 
exclamativas que expresan amenazas o malos deseos. Un apunte respecto al texto de base: con una convicción casi militante, Bulbena utiliza la reciente edición de Celestina de Julio Cejador (Madrid, 1913), según reza en el prefacio. Lorenzo Blini ${ }^{11}$ argumenta a favor de la necesidad de una edición crítica clara para el traductor, arguyendo que Celestina es una de las obras clásicas que más problemas ha conllevado a los traductores italianos. Bulbena se enfrenta al mismo escollo, aunque no parece dudar de qué edición escoger. En lo que respecta a la traducción, los lectores de la versión bulbenística se ahorran esta dificultad, puesto que se realizó una única edición de cien ejemplares de bibliógrafo: D'aquesta obra se n-han tirat sols un centenar d'exemplars, dels quals n'hi hà quatre en paper japonès, tóts numerats. (p. Iv).

Sin embargo, sí nos parece pertinente recordar los rasgos principales de esta traslación, así como presentar brevemente al traductor.

\section{El traductor: esbozo biobibliogràfico}

Antoni Bulbena (Barcelona, 1854 - La Garriga,1946) era esencialmente un intelectual a la antigua, bibliófilo, lexicógrafo y amante de las letras, en especial de las clásicas. Utilizó a menudo los seudónimos de Antoni Tallander, Mossèn Borra y Ali-Ben-Noab Tun. Formó parte de un reducido grupo de intelectuales que no quería arrodillarse ante las nuevas normas ortográficas de Pompeu Fabra y del Institut d'Estudis Catalans. Fabra acababa de publicar, en 1912, su Gramática de la lengua catalana, mientras que las Normes ortogràfiques son de 1913, aunque ya existían las normas de la revista $L^{\prime} A v e n c ̧$. Su rebeldía la expresaba con el uso de un catalán arcaizante en toda su obra, inspirado en el Tirant lo Blanch (1460), una obra casi contemporánea de Celestina, redactada, según indica en el prefacio (Advertencia) a su traslación, en «lo mes pur catalanesch, com a llenguatge únich e oficial, en aquella època, tant per Catalunya, com per Valencia, Rosselló e Mallorques». Pero su entusiasmo medievalizante y su ideal de lograr una lengua catalana estándar por encima de los dialectos, como en tiempos antiguos, tenía ya pocos adeptos en el segundo decenio del siglo xx. Esta postura contra corriente, anti-orsiana (Eugeni d'Ors) y antinoucentista fue una de las causas del olvido al que ha sido relegado Bulbena, a pesar de la magnitud de su obra. Así, la recepción crítica de su versión celestinesca es prácticamente nula ${ }^{12}$. Aparece sólo citada, sin comentarios, en las frecuentes reseñas que el propio Bulbena realizaba de

11.- Blini, Lorenzo. "La crítica textual como herramienta del traductor de textos antiguos: el caso de las versiones italianas modernas de La Celestina», en Morillas, Esther y Álvarez, Jesús (eds), Las herramientas del traductor. Málaga: Ediciones del Grupo de Investigación Traductología, 2000, pp. 61-90.

12.- Ugarte, Xus. La traducció de parèmies. Bellaterra: Universitat Autònoma de Barcelona, 1998, [Tesis doctoral], p. 340 
sus escritos. La única precisión, que a nuestro parecer no aporta ninguna información destacable, la encontramos en el manuscrito Recorts d'un barceloní octogenari ecziliat a La Garriga ${ }^{13}$, una recapitulación de su vida y obra llevada a cabo durante los años de la guerra civil (1936-1939). Efectivamente, existen pocas referencias sobre Bulbena en historias de la literatura; cuando se le cita, es para destacar su postura antinormativa o a veces su falta de rigor en la edición o traducción de textos. No iríamos desencaminados si afirmáramos que se le ha citado más en estudios del siglo XXI que del xx: los trabajos académicos de historia de la traducción al catalán, de bibliografía o edición de clásicos topan forzosamente con la obra de un Antoni Bulbena que abrazó todos los campos del saber filológico.

\section{Bulbena traductor}

El traductor de Celestina llevó al catalán grandes obras de autores antiguos y grandes clásicos de lenguas muy dispares, con el objetivo de renovar la literatura en esta lengua. Destacan La Divina Comedia de Dante (1908), Hamlet, princep de Denamarca de Shakespeare y obras de Zola, Tolstoi, Musset, Homero o Esquilo. Para obras de lenguas más exóticas, como Les mil i una nits o el poema indio Mahabharata, utilizó a menudo la traducción francesa como texto de partida.

Su predilección por los clásicos castellanos fue notable. Además de Comedia de Calist i Melibea (La Celestina) en 1914, publica varias versiones de El Quixot (18914, 1894, 1928, 1939, 1936), el Llàtzer de Tormes (1892) - que él atribuye a Diego Hurtado de Mendoza- , tres novelas ejemplares de Cervantes (Raconet e Talladell en 1895 y Lo Casori Enganyador; seguit del col.loqui dels cans Scipió \& Bergança en 1930) y, en un librito de divulgación religiosa, el poema castellano del siglo XIV La Dança de la Mort, según un manuscrito del siglo XV de El Escorial ${ }^{15}$.

Bacardí, en la presentación a El Quixot ${ }^{16}$ bulbenístico de 2005 afirma que esta obra se convirtió en el libro de su vida y que lo reescribió en catalán a lo largo de cincuenta años, entre traducciones enteras o parciales,

13.- Bulbena, Antoni. Recorts d'un barceloní octogenari ecziliat a La Garriga. Dietari (1936-1940), MS 3244, BC. "... «La Celestina», traducida segons les lliçons rebudes del Dtor Balari, mon colaborador en lo Llàtzer de Tormes", p. 35.

14.- En 2005, para conmemorar el cuarto centenario del Quijote, se edita la versión íntegra de 1891: Cervantes, L'Enginyós Cavaller Don Quixot de la Mancha. Barcelona: Edicions 62, 2005. Traducción de Antoni Bulbena i Tusell (1891). Prólogo de Joan Givanel i Mas (1891). Presentación de Montserrat Bacardí (2005).

15.- Ugarte Ballester, Xus. «Antoni Bulbena, traductor prolífico de clásicos castellanos al catalán: algunas traducciones inéditas", en: Vega Cernuda, Miguel Ángel (ed). La traducción de los clásicos: problemas y perspectivas. Madrid: Instituto Universitario de Lenguas Modernas y Traductores, 2005, pp. 27-28.

16.- Cervantes 2005, op. cit., pp. 8-9. 
adaptaciones, inéditas o publicadas. De hecho, se convirtió en su libro de cabecera y, en definitiva, en una obstinación personal. La fascinación de Bulbena por Cervantes le llevó a traducir todas las novelas ejemplares, aunque sólo salieron a la luz las anteriormente mencionadas. Lo curiós impertinent y La tia fingida, ambas de 1937, pueden consultarse en la Biblioteca de Catalunya (BC) como Manuscrito (MS) 1445.

Entre otras versiones inéditas de clásicos castellanos ${ }^{17}$ citemos Romances Raurich de Vivar (MS 3253, BC, 1938), Romancer rondallistic. Romancer moresch. (MS 3255, BC, 1938).

\section{Bulbena editor}

Otra faceta de Bulbena, ya mencionada, es la de bibliógrafo y gramático incansable. En 1907 inicia la Biblioteca Clàssica Catalana. Entre los clásicos editados figuran Ausiàs March, Tomic, Bernat Metge, Isabel de Villena, Vicenç Garcia, Eiximenis o Joanot Martorell. Por otro lado, gran parte de su actividad como editor de obras antiguas tiene un gran interés para el estudio del folklore catalán. Citemos Romancer català popular (1900), Llegendari català (1902) y una extensa Bibliografia paremiològica catalana (1915). De su trabajo como lingüista destacan diversos estudios sobre la lengua catalana y diccionarios plurilingües que combinaban el catalán, el castellano y el francés ${ }^{18}$.

Esta misión redentora filológica y editorial para uposar lo nostre idioma ben alt e al lloch que per dret li correspon", según reza en la Advertencia o prefacio a su versión de Celestina, no se limita al lenguaje culto y literario y a las gramáticas. Así, nuestro lexicógrafo publica y recopila vocabulario de distintos ámbitos temáticos contemporáneos o de obras medievales, algunos de ellos seguramente censurables, por cierto, por la sociedad de su época. En diecisiete obras autoeditadas ${ }^{19}$ (Impremta particular de l'editor, Impremta del XXèn segle, A. Bulbena, Biblioteca eròtica i priàpica) en la ciudad de Erotòpolis [i.e. Barcelona] entre los años 1900 y 1920, Bulbena pretende rescatar del olvido la literatura erótico-picaresca, tanto catalana como extranjera. La distribución era muy restringida y destinada a los Infiernos bibliófilo

\section{7.- Ugarte 2005, op. cit., p. 33.}

18.- Para un elenco completo de su extensa bibliografía publicada, ver: Entrada «Antoni Bulbena i Tusell» (2011). Xus Ugarte (redactora) en: Bacardí, Montserrat; Godayol, Pilar (dir). Diccionari de la traducció catalana. Eumo Editorial, UAB, UIB, UJI, UVic, pp. 97-99.

19.- Ver nota 16. Citemos, no obstante, como muestra, Rondalles e facécies lliures dels pobles de Llengadoch: folklore eròtic (1920); Flora pornogräfica francesa. Suplement al argot francès / Flore pornographique catalane. supplément à l'argot catalan (manuscrito 1891-1910); Paremiología catalana sóbre la Amor, la Fémbra e lo Matrimoni. Barcelona: Imprempta Catalonia, 1915 
de tema erótico, en parte como se realizaba en Francia, país en el que las tiradas eran mayores e iban ilustradas con imágenes ${ }^{20}$.

Esta vasta investigación contribuyó muy probablemente a enriquecer el vocabulario necesario para trasladar al catalán el lenguaje pícaro y a veces soez de Celestina. Nos ocupamos seguidamente de los adjetivos descalificadores y de los insultos en forma de frases de maldición.

\section{Los adjetivos descalificadores en la versión catalana}

Destaquemos, por un lado, la fidelidad de Bulbena al original —traduce prácticamente todos los adjetivos, no hay autocensura- y, por otro, la licencia creativa que se otorga a sí mismo como trujamán. No escribe a menudo el equivalente fácil, exacto, de la misma raíz etimológica, sino que busca sinónimos arcaicos y poco comunes.

Veámoslo en la estadística siguiente. La Celestina original cuenta con 167 adjetivos descalificadores (66 variantes de epítetos descalificadores), mientras que Bulbena (16 actos) cuenta con $158^{21}$ y 77 variantes, es decir, introduce 11 sinónimos adicionales. A continuación detallaremos cuáles son:

1. Las 7 versiones de necio (3 veces), necia (3 veces), neciuelo (1 vez) quedan repartidas entre los siguientes epítetos: Taboll i taujà (necio); Bajanet (neciuelo); omisión de la traducción en necia y tres párrafos más (acto VII); omisión de "necia», pero compensada con dos sinónimos de desaliñada en la retahíla de Areúsa (acto IX): xarxota, dexada.

2. El adjetivo preferido de los personajes es loco con sus variantes loca, loquillo, loquilla, loquito. En la Tragicomedia lo profieren 26 veces. De nuevo, sólo 17 apariciones de boig (boja, boget, bojeta, bojot, boget, més que boig) en Bulbena. Las 8 restantes, taboll, foll/a (6), trastocat. Bulbena apuesta sobre todo por fóll, ya que es un sinónimo total, más arcaico y culto, de boig.

3. Bobo (8 veces en el original) y cinco en la versión catalana: baboya (2), babau (3), además de bajanaç, ximplet, ximpleta.

4. Para vellaco el catalán cuenta con buen número de adjetivos que evocarían el mismo sentido (bergant, brètol, brivall, truà, pillard). Ahora bien, sí usa bergant una vez, pero prefiere el arcaico bricó y briconet. Bricó es un adjetivo arcaico, localizado sólo en diccionarios del siglo xIX, considerado ya antiguo. El Diccionari català-castellà-

20.- Blog Piscolabum librorum maioris, 8 de marzo de 2010, L'erotisme bibliófil català, Antoni Bulbena $i$ Tosell. (http://piscolabislibrorumadults.blogspot.com/2010/03/lerotisme-bibliofil-catalaantoni.html?zx=45733059a83df0eb).

21.- La diferencia entre 167 y 158, adjetivos descalificadores, se desglosa en: 4 omisiones en los párrafos o frases en la versión catalana, una omisión ordinaria y transformación sintáctica de estos adjetivos. 
Ilatí- francès-italià22 lo define como bribó (bribón), palabra que no aparece en los diccionarios actuales de la lengua catalana al ser considerada un barbarismo.

\section{Las frases}

Analicemos en primer lugar la composición léxica y sintáctica de las frases que sirven de insulto a los personajes celestinescos. Hemos tomado como base el Acto I, dado que es el más largo y, por tanto, el que más frases contiene. Incluimos ejemplos de otros actos sólo si aparece una estructura enunciativa ausente en el primero. Hemos recogido 10 estructuras distintas para expresar malos deseos. Incluimos la traducción, con dos tipos de comentario: «AB: misma estructura» $\mathrm{O}$, en caso contrario, señalamos la opción de Antoni Bulbena (AB).

1. Frase exclamativa Ansí + subjuntivo. jAnsí los diablos te ganen! (Acto I) $\mathrm{AB}$ : misma estructura. jAxí te sén duguen los diables!

En cambio, en jAnsí te medre Dios...! (Acto I) AB cambia a iBona la havèm feta!, una frase hecha ya repertoriada en catalán y con idéntico sentido al original.

2. Frase exclamativa adjetivo + subjuntivo. jMaldito seas, que me has hecho reír...! (Acto I)

$\mathrm{AB}$ : misma estructura. jMalehit sigues, que m'has fet riure...!

¡Quemada seas...! (Acto I). AB: Axí + subjuntivo: jAxí-t veges cremada...!

3. Frase exclamativa Imperativo + adjetivo. jVed qué torpe y qué comparación! (Acto I); AB: misma estructura ¡Mirau quía barrohera e quina comparança!.

4. Frase exclamativa Imperativo + complemento adverbial: ¡Vete de aquí a la mala ventura! (Acto VI); AB: misma estructura. jVés-tén d'ací en ta mala ventura!

5. Frase exclamativa Nunca + subjuntivo. ¡Nunca Dios te vea, nunca Dios te consuele ni te visite! (Acto I). AB: quizás para evitar una repetición, el traductor combina $A x i$ + subjuntivo y may + subjuntivo: ¡Axí Déu no-t veja, ni may no-t visit ni do consol!

6. Frase exclamativa ; $O+$ que + sustantivo: ¡O qué plaga, o qué enojo! (Acto I). AB: ¡Oh quin flagéll! ¡Oh quin enuig!

7. Frase exclamativa sustantivo + subjuntivo. ¡Postema y landre te mate, etc (Acto I); iLos ojos se te salten! (Acto I); jFuego malo te queme! (Acto I); ;Mala landre te mate! (Acto I); iMas rabia mala me mate! (Ac- 
to I); ¡Putos días vivas...! (Acto I). La traducción de $\mathrm{AB}$ conserva la misma estructura en todos ellos excepto en «...rabia», que se convierte en que + sustantivo+ subjuntivo (iQue de mala rábia jo muyra...!): Postérma e glànola quét mat/ foch d'infern que-t crém/, Mala bua que't corsech / iPutaners dies visques...!,

8. Frase exclamativa adverbio (tiempo, lugar) + verbo (futuro, subjuntivo). ¡Allá irás con el diablo! (Acto II); ... en malhora a ti he yo menester (Acto III).

$\mathrm{AB}$ introduce "que + subjuntivo» (; Que se te-n duga lo diable!), ;... en mala hora si éts tu lo companyó que-m cal!, en una versión algo más libre que transmite el mensaje, sin conservar el léxico.

9. Que + adjetivo + sustantivo: Que maldito sea... (Acto IV); AB: Que malehit sia...

10. Frase exclamativa futuro + complementos: ;Te echaré dende con el diablo! (Acto VI); AB: misma estructura T'etgegaré d'ací ab lo diable!

Ya hemos comprobado que en algunos de estos ejemplos ofrecidos $y$, a lo largo de todo el corpus, Bulbena intenta enriquecer o variar el ya de por sí intenso vocabulario del original. En este sentido, las versiones de (Mala) landre te mate representan una muestra muy ilustrativa:

- en el Acto I encontramos dos traslaciones: glànola quét mat, una expresión que no está repertoriada como frase hecha o locución, así que tenemos dudas de su efecto en el lector; más adelante se transforma en ¡Mala bua quét corsech!;

- en el acto Iv es Mala pésta que-t mat y, en el Acto viI, Que-m cayga ací morta, si t'entenia y, a continuación, iJa-m fira un llamp!, Que de glànola muyra (Acto XI); mala bua m'atuhesca (Acto XIV) Es decir, seis variantes para esta frase que, según el DRAE, «expresa desprecio, apartamiento, malos deseos, para la persona a quien se dirige».

A su vez, parece apostar por la forma $A x i ́$ subjuntivo y que + subjuntivo. El diablo y las enfermedades más crueles, tanto en el original como en la traducción, parecen ser una de las evocaciones favoritas de los personajes.

\section{Arcaísmos en la traducción}

Hemos citado de sobra el ideal arcaizante de Bulbena en lo que se refiere al lenguaje. Incluimos aquí algunos ejemplos para ilustrar este criterio, a partir del cuadro de des-calificativos objeto de nuestro estudio. Para verificar su vigencia hemos recurrido a varios diccionarios de 
la lengua catalana (monolingües, bilingües o plurilingües) publicados en $1806^{23}, 1839^{24}, 1854^{25}, 1993(1962)^{26}, 1995^{27}$.

Únicamente indicamos la fuente cuando no aparece, ni como forma moderna o arcaica, en el Diccionari IEC ( Diccionari de l'Institut d'estudis catalans) de 1995.

- Baboya (boba): no se encuentra referenciada en ningún diccionario. Sí está en cambio repertoriada baboia.

- Bajanaç (bobo): no aparece repertoriado el aumentativo, aunque sí bajà-ana.

- Bardaixó (putillo): no aparece repertoriado el diminutivo, aunque sí bardaix, con la definición de "sodomita»

- Dessaborit (desabrido): en el diccionario de 1839 aparece ya como antiguo, equivalente a persona de mal genio y condición. Actualmente, dessaborit se refiere especialmente a la falta de sabor en la fruta.

- Enemich (enemigo): actualmente enemic, aparece también con ch final en 1806 y como enemig en 1854.

- Maldihent (maldeziente): actualmente maldient. Ningún diccionario recoge la acepción con la h intercalada.

- Malehit, maleyt (maldito): actualmente, maleit. En 1854 aparece maleid.

- Pahoruch (pusillanime): actualmente poruc y, como ant., pahuruc (Dicc. 1993)

- Pahorugues (fem. pl. de pahoruch) se encuentra en una cita de Bernat Metge del siglo XV (dicc. 1993).

- Putana (puta): nombre antiguo (Dicc 1993), alternada en la traducción con puta.

- (Mala) Fembra (mujer): nombre antiguo por dona o femella.

- Fólla fembra: antiguo por prostituta.

23.- Diccionario manual de la lengua catalana y castellana, arreglado por Agustín Antonio Roca y Cerdá. Barcelona: Compañía Jordi, Roca, Gaspar, 1806.

24.- Véase nota 20.

25.- Diccionario catalán-castellano (Magí Ferrer). Barcelona: Impremta y Librería de Pablo Riera, 1854.

26.- Diccionari català-valencià-balear: inventari lexicogràfic i etimològic de la llengua catalana en totes les seves formes literàries i dialectals, obra iniciada por Antoni Maria Alcover, redactada por Francesc de B. Moll (1962), con la colaboración de Manuel Sanchis Guarner y de Anna Moll Marquès. Palma: Moll, 1993, 10 vols..

27.- Diccionari de la llengua catalana. Barcelona: Institut d'Estudis Catalans, 1995. 
Finalmente, he aquí otros ejemplos significativos de escritura anterior a la reforma de Pompeu Fabra que hallamos en el corpus y que aparecen en el diccionario de 1806 (Diccionario manual de la lengua catalana y castellana) señalamos cuando están repertoriadas en los diccionarios de cronología posterior. Las formas modernas (amb, així, raó etc) no aparecen en el mencionado diccionario.

- $A b$ (con), forma antigua de amb (dicc 1854).

- Axí (asî), axo (esto, eso); actualmente con $i$ intercalada para guardar el sonido fricativo. En la lista de adjetivos, véase también: exelebrat (desatinado), dexada (desaliñada) actualmente eixelebrat y deixada.

- Otro rasgo arcaico que Bulbena insiste en utilizar es la $h$ intercalada:

- rahó (razón): actualmente raó. (dicc. 1839 y 1854).

- Spay (espacio): actualmente espai. 1806; espay en 1839 y 1854.

- Llarch (largo): actualmente llarg en 1839

- Trobayre (occitano por trovador): actualmente trobador. Aparece sólo con la forma trobaire.

\section{Conclusión}

A guisa de conclusión, podríamos afirmar que Antoni Bulbena no parece tener dificultades en la traslación de la lengua viperina de los personajes celestinescos. Su tarea de investigación lexicográfica a lo largo de toda la vida debió de jugar a favor de la riqueza verbal de la versión, aumentada en cantidad respecto al original de adjetivos y frases des-calificativos analizados. Si esta es copiosa, en nuestra modesta opinión, el colorido y especializado repertorio erótico-amoroso y erótico-profesional de los personajes celestinescos se ve adecuadamente trasladado a la lengua catalana. Pero esta aseveración sería objeto de un análisis paralelo que no se corresponde con el tema que ahora nos concierne, el de los insultos.

En efecto, la base de nuestra aportación en este artículo se presenta a continuación en el anexo: una vez vaciados todos los adjetivos descalificadores y frases de maldición de los actos I-XVI de la versión castellana, los hemos cotejado con sus equivalentes en catalán, en traducción de Antoni Bulbena. 


\section{Bibliografía citada}

AlbuiXeCH, Lourdes. «Insultos, pullas y vituperios en Celestina». Celestinesca 25.1-2, 2001: 57-68.

BaCARdí, Montserrat. "Presentació» en: Cervantes, L'Enginyós Cavaller Don Quixot de la Mancha. Barcelona: Edicions 62, 2005. Traducción de Antoni Bulbena i Tusell (1891), pp. 7-10.

BatTin, Mijail. La cultura popular en la Edad Media y el Renacimiento. El contexto de François Rabelais. Barcelona: Barral, 1974. Traducción de Julio Forcat y César Conroy.

Blini, Lorenzo. "La crítica textual como herramienta del traductor de textos antiguos: El caso de las versiones italianas modernas de La Celestina», en: Morillas, Esther y Álvarez, Jesús (eds), Las herramientas del traductor. Málaga: Ediciones del Grupo de Investigación Traductología, 2000, pp. 61-90.

Bulbena, Antoni. "Advertencia», en: Rojas, Fernando de. Comedia de Calist \& Melibea (La Celestina). Barcelona: Stampa de la Vda Badia, 1914, p. V-VIII. Traducción de Antoni Bulbena.

- Flora pornogràfica francesa. Suplement al argot francès / Flore pornographique catalane. supplément à l'argot catalan (manuscrito 1891-1910).

- Paremiología catalana sóbre la Amor, la Fémbra el lo Matrimoni. Barcelona: Imprempta Catalonia, 1915.

- Rondalles e facécies lliures dels pobles de Llengadoch: folklore eròtic. Erotòpolis (Barcelona): Impremta particular del Editor, 1920.

- Recorts d'un barceloní octogenari ecziliat a La Garriga. Dietari (1936-1940), MS 3244, BC.

Cervantes, Miguel de. L'Enginyós Cavaller Don Quixot de la Mancha. Barcelona: Edicions 62, 2005. Traducción de Antoni Bulbena i Tusell (1891).

Di Camillo, Ottavio. "Etica humanística y libertinaje», en: López Ríos, Santiago (ed). Estudios sobre la Celestina. Madrid: Istmo. 2001, pp. 579600.

DiCCIONARI català-castellà-llatí- francès-italià. Barcelona: Imprenta Joseph Torner, 1839.

DiCCIONARI català-valencià-balear: inventari lexicogràfic i etimològic de la llengua catalana en totes les seves formes literàries i dialectals, (Alcover-Moll), 10 vols. Palma: Moll, 1993.

DiCCIONARIO catalán-castellano. (Magí Ferrer). Barcelona: Impremta y Librería de Pablo Riera, 1854. 
DicCiONARIO manual de la lengua catalana y castellana, arreglado por Agustín Antonio Roca y Cerdá. Barcelona: Compañía Jordi, Roca, Gaspar, 1806.

GAZOPHYLACIUM. <http://lexicografia.blogspot.com/2010/03/lextravagant lexicograf-antoni-bulbena.html> Bloc amateur sobre lexicografia catalana $i$ altres lletraferidures [consulta noviembre 2010]

LaCARRa Lanz, Eukene. "Sobre los dichos 'lascivos y rientes'», en: López Ríos, Santiago (ed). Estudios sobre la Celestina. Madrid: Istmo, 2001, pp. 355- 380.

—. "La ira de Melibea a la luz de la filosofía moral», en Beltrán, Rafael y Canet, José Luis (eds). Cinco siglos de Celestina. Valencia: Universitat de València, 1997, pp. 107-120.

PISCOLABUM librorum maioris (blog) <http://piscolabislibrorumadults.blogspot.com/2010/03/lerotisme-bibliofil-catala-antoni. html?zx=45733059a83df0eb $>$. L'erotisme bibliòfil català, Antoni Bulbena $i$ Tosell [consultado noviembre 2010].

RojAs, Fernando de. Comedia de Calist \& Melibea (La Celestina). Barcelona: Stampa de la Vda Badia, 1914. Traducción de Antoni Bulbena.

—. La Celestina. Ed. Dorothy S.Severin. Madrid: Cátedra, 1997.

Severin, Dorothy. "El humor en La Celestina», en López Ríos, Santiago (ed). Estudios sobre la Celestina. Madrid: Istmo, 2001, pp. 327-354.

Ugarte Ballester, Xus. La traducció de parèmies. Bellaterra: Universitat Autònoma de Barcelona, 1998. [Tesis doctoral, inédita]

—. "La traducción catalana de Celestina», Celestinesca 27 (2003): 165-210.

- «Antoni Bulbena, traductor prolífico de clásicos castellanos al catalán: algunas traducciones inéditas», en Vega Cernuda, Miguel Ángel (ed). La traducción de los clásicos: problemas y perspectivas. Madrid: Instituto Universitario de Lenguas Modernas y Traductores, 2005, pp. 27-38.

—. Entrada "Antoni Bulbena i Tusell», en Bacardí, Montserrat; Godayol, Pilar (dir). Diccionari de la traducció catalana. Eumo Editorial: UAB, UIB, UJI, UVic, pp. 97-99. 


\section{FERRAN DE RÒJAS}

\section{Comedia}

de

\section{Calist \& Melibea}

(LA CELESTINA)

Per primera volta en català literalment

traduhida de la edició original autèntica

per

ANTONI BULBENA \& TOSELL
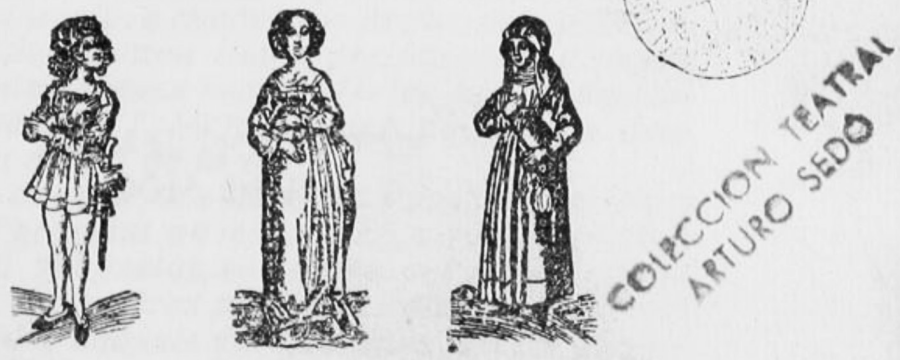

BARCELONA

Stampa de la Vda. Badia.-Carrer d'en Dou, 14.

M.CM.XIV 


\section{Anexo}

\section{Tabla de adjetivos descalificadores y maldiciones personales en Celestina y en la traducción catalana de Antoni Bulbena}

\begin{tabular}{|c|c|c|c|c|}
\hline & PERSONAJE & $\begin{array}{c}\text { A quién se dirige } \\
\text { o a quién se } \\
\text { refiere }\end{array}$ & $\begin{array}{c}\text { Original } \\
\text { CASTELLANO }\end{array}$ & $\begin{array}{l}\text { Traducción } \\
\text { CATALANA }\end{array}$ \\
\hline \multirow[t]{14}{*}{$\begin{array}{c}\text { Acto } \\
\text { I }\end{array}$} & Calisto & A Sempronio & $\begin{array}{l}\text { ¿Dónde está este } \\
\text { maldicto? }\end{array}$ & ¿On és aquest malehit? \\
\hline & Calisto & A Sempronio & $\begin{array}{l}\text { ¡Ansí los diablos } \\
\text { te ganen!, ansí por } \\
\text { infortunio arrebatado } \\
\text { perezcas, o perpetuo } \\
\text { intolerable tormento } \\
\text { consigas... ¡Anda, anda, } \\
\text { malvado...! }\end{array}$ & $\begin{array}{l}\text { ¿Axí te se'n duguen } \\
\text { los diables! ¡Axí per } \\
\text { malastre arrapat } \\
\text { peresques o perpetual } \\
\text { incomportable torment } \\
\text { atenyes... } \\
\text { ¡Vé, vés, malvat! }\end{array}$ \\
\hline & Calisto & A Sempronio & ¡Ve con el diablo! & ¡Vés-te-n ab lo diable! \\
\hline & Sempronio & Aparte & Loco está este mi amo & $\begin{array}{l}\text { Tinch boig lo meu } \\
\text { senyor }\end{array}$ \\
\hline & Calisto & Sempronio & $¡$ ¡ grossero! & ¡Oh groller! \\
\hline & Calisto & A Sempronio & $\begin{array}{l}\text { ¡Maldito seas! Que } \\
\text { hecho me has reyr }\end{array}$ & $\begin{array}{l}\text { ¡Malehit sigues, que } \\
\text { m'has fet riure }\end{array}$ \\
\hline & Sempronio & $\begin{array}{l}\text { (Aparte) a } \\
\text { Calisto }\end{array}$ & $\begin{array}{l}\text { ¡Oh pusillánime, o fi de } \\
\text { puta! }\end{array}$ & $\begin{array}{l}\text { ¡Oh pahoruch! ¡Oh fill } \\
\text { de puta! }\end{array}$ \\
\hline & Calisto & A Sempronio & $\begin{array}{l}\text { ¡Maldito sea este necio, } \\
\text { y qué porradas dice! }\end{array}$ & $\begin{array}{l}\text { ¡Malehit sia aqueix } \\
\text { taboll! ¡E quines } \\
\text { magallades diu! }\end{array}$ \\
\hline & Sempronio & $\begin{array}{l}\text { Sobre las } \\
\text { mujeres }\end{array}$ & $\begin{array}{l}\text { Arma del diablo, cabeza } \\
\text { de pecado, destrucción } \\
\text { de paraíso... }\end{array}$ & $\begin{array}{l}\text { Arma del diable, cap } \\
\text { de pecat, destrucció de } \\
\text { paradís... }\end{array}$ \\
\hline & Sempronio & Calisto & $\begin{array}{l}\text { ¡O qué plaga, oh qué } \\
\text { enojo. Oh qué fastío es } \\
\text { conferir con ellas..." }\end{array}$ & $\begin{array}{l}\text { ¡Oh quin flagéll } \\
\text { ¡oh quin enuig! ¡Oh } \\
\text { quin fastig ab élles } \\
\text { conversar ..." }\end{array}$ \\
\hline & Sempronio & (Aparte) & $\begin{array}{l}\text { (¡Qué mentiras, y qué } \\
\text { locuras dirá agora este } \\
\text { cativo de mi amo!) }\end{array}$ & $\begin{array}{l}\text { ¿Quines mentides e } \\
\text { quines bogeries no dirà } \\
\text { are aqueix dolent de } \\
\text { senyor méu! }\end{array}$ \\
\hline & Sempronio & $\begin{array}{l}\text { (Aparte) } \\
\text { Calisto }\end{array}$ & ¡Ansí te medre Dios... & ¡Bona la havèm féta! \\
\hline & Calisto & A Sempronio & $\begin{array}{l}\text { ¡Ved qué torpe y qué } \\
\text { comparación! }\end{array}$ & $\begin{array}{l}\text { Mirau quía barrohera e } \\
\text { quina comparança! }\end{array}$ \\
\hline & Sempronio & $\begin{array}{l}\text { (Aparte) } \\
\text { Calisto }\end{array}$ & $\begin{array}{l}\text { ¡En sus treze está este } \\
\text { necio! }\end{array}$ & $\begin{array}{l}\text { ¡En los seus trétze stà } \\
\text { aqueix tabóll! }\end{array}$ \\
\hline
\end{tabular}

1.- Hemos incluido en una sola celda diversos descalificativos o improperios cuando se trata de la misma intervención del mismo personaje. 


\begin{tabular}{|c|c|c|c|}
\hline Elicia & A Sempronio & $\begin{array}{l}\text { ¡Ay, maldito seas, } \\
\text { traydor! Postema y } \\
\text { landre te mate, y a } \\
\text { manos de tus enemigos } \\
\text { mueras, y por crímenes } \\
\text { dignos de cruel muerte } \\
\text { en poder de rigurosa } \\
\text { justicia te veas. }\end{array}$ & $\begin{array}{l}\text { ¡Maleyt sies, traydor! } \\
\text { Postérma e glànola } \\
\text { quét mat, e a mans } \\
\text { dels teus enemichs } \\
\text { deixs tu la pell e, per } \\
\text { crims de cruel mort, } \\
\text { en podèr de rigorósa } \\
\text { justícia te veges. }\end{array}$ \\
\hline Elicia & A Sempronio & $\begin{array}{l}\text { ¡Nunca Dios te vea, } \\
\text { nunca Dios te consuele } \\
\text { ni te visite! }\end{array}$ & $\begin{array}{l}\text { ¡Axí Déu no-t veja, ni } \\
\text { may no-t visit ni do } \\
\text { consol! }\end{array}$ \\
\hline Celestina & A Sempronio & $\begin{array}{l}\text { Deja esa loca, que es } \\
\text { liviana }\end{array}$ & $\begin{array}{l}\text { Deixa aquesta boja, qui } \\
\text { és lleugera }\end{array}$ \\
\hline Elicia & A Sempronio & $\begin{array}{l}\text { ¡Ha, don malvado! ¡Los } \\
\text { ojos se te salten! }\end{array}$ & $\begin{array}{l}\text { ¡Ah, en malvat! ¡Los } \\
\text { ulls perdésses! }\end{array}$ \\
\hline Calisto & A Pármeno & ¿No oyes, maldito sordo? & $\begin{array}{l}\text { ¿No-u sents, malehit } \\
\text { sórt? }\end{array}$ \\
\hline Pármeno & Calisto & Puta vieja alcoholada & Puta vella alcofollada \\
\hline Calisto & A Pármeno & Calla, calla, malvado & Calla, calla, malvat \\
\hline Celestina & A Pármeno & $\begin{array}{l}\text { ¡Neciuelo, loquito, } \\
\text { angelico, perlica, } \\
\text { simplecico! ¿Lobitos en } \\
\text { tal gestico? } \\
\text {...putico } \\
\text { ¡Mas rabia mala me } \\
\text { mate...! }\end{array}$ & $\begin{array}{l}\text { ¡Bajanet, boget, } \\
\text { angelet, perleta méua, } \\
\text { ximplonet! } \\
\text { ¿A mi fent de llobarret } \\
\text { furiós? } \\
\text {...puteret } \\
\text { ¡Que de mala rábia jo } \\
\text { muyra...! }\end{array}$ \\
\hline Celestina & Pármeno & ¡ malvado! & ¡Oh mesquí! \\
\hline Pármeno & Celestina & flaca puta viej & Feble puta vélla \\
\hline Celestina & Pármeno & $\begin{array}{l}\text { ¡Putos días vivas, } \\
\text { vellaquillo! }\end{array}$ & $\begin{array}{l}\text { ¡Putaners dies visques, } \\
\text { briconet! }\end{array}$ \\
\hline Celestina & Pármeno & $\begin{array}{l}\text { ¡Pues fuego malo te } \\
\text { queme, que tan puta } \\
\text { vieja era tu madre como } \\
\text { yo! } \\
\text {... loquito }\end{array}$ & $\begin{array}{l}\text { ¡Donchs foch d'infern } \\
\text { que-t crém, que tan } \\
\text { vélla puta éra ta mare } \\
\text { com jo! } \\
\text {... boget }\end{array}$ \\
\hline Celestina & Pármeno & $\begin{array}{l}\text { ¡Mala landre te mate! ¡Y } \\
\text { cómo lo dice el } \\
\text { desvergüençado! }\end{array}$ & $\begin{array}{l}\text { ¡Mala bua quét } \\
\text { corsech! ¡E com ho diu } \\
\text { lo desvergonyit! }\end{array}$ \\
\hline Celestina & A Pármeno & $\begin{array}{l}\text { Oh mezquino! (...) } \\
¡ O \text { simple! }\end{array}$ & $\begin{array}{l}\text { ¡Oh mesquí! (...) } \\
\text { ¡oh ximplet! }\end{array}$ \\
\hline Celestina & A Pármeno & $\begin{array}{l}\text { ¿Qué es razón, loco? } \\
\text { ¿Qué es affecto, asnillo? }\end{array}$ & $\begin{array}{l}\text { ¿Que-m véns ab la } \\
\text { rahó, boig? ¿Què és axò } \\
\text { d'afécte, asenet? }\end{array}$ \\
\hline
\end{tabular}




\begin{tabular}{|c|c|c|c|c|}
\hline \multirow[t]{7}{*}{ Acto II } & Calisto & Sempronio & ¿Cómo, simple? & ¿Què dius are, beneyt? \\
\hline & Calisto & Pármeno & ¿Qué dixiste, enojoso? & $\begin{array}{l}\text { ¿Què deyes sus-are ab } \\
\text { enuig? }\end{array}$ \\
\hline & Calisto & Pármeno & ¿Cómo, loco, su cativo? & $\begin{array}{l}\text { ¿Còm, lo seu esclau, més } \\
\text { que boig? }\end{array}$ \\
\hline & Calisto & Pármeno & ¡Algo dice el necio! & $\begin{array}{l}\text { Quelcom stà dihent lo } \\
\text { taujà }\end{array}$ \\
\hline & Calisto & Pármeno & $\begin{array}{l}\text { ¡Palos querrá ese vellaco! } \\
\text { Di, mal criado }\end{array}$ & $\begin{array}{l}\text { ¡Cerca aqueix bergant } \\
\text { qué1 bastonegen! Digues, } \\
\text { malcriat }\end{array}$ \\
\hline & Calisto & Pármeno & ¡Calla,calla, perdido! & ¡Calla, calla, perdulari! \\
\hline & Pármeno & A sí mismo & $\begin{array}{l}\text { Más nunca sea; jallá irás } \\
\text { con el diablo! A estos } \\
\text { locos decildes }\end{array}$ & $\begin{array}{l}\text { ¡Ni mai que tornasses! } \\
\text { ¡Que se te-n duga lo } \\
\text { diable! A semblants fólls } \\
\text { digau-los... }\end{array}$ \\
\hline \multirow[t]{3}{*}{$\begin{array}{c}\text { Acto } \\
\text { III }\end{array}$} & Sempronio & A sí mismo & $\begin{array}{l}\text { ¡Qué spacio lleva la } \\
\text { barbuda; }\end{array}$ & $\begin{array}{l}\text { !Mirau quant va de spay } \\
\text { la barbuda! }\end{array}$ \\
\hline & Celestina & Sempronio & $\begin{array}{l}\text { ¡Alahé, en mal hora a ti } \\
\text { he yo menester...” }\end{array}$ & $\begin{array}{l}\text { ¡A fè que en mala hora si } \\
\text { éts tu lo companyó que-m } \\
\text { cal! }\end{array}$ \\
\hline & Celestina & Elicia & Calla, boba & Calla, ximpleta \\
\hline \multirow[t]{10}{*}{$\begin{array}{l}\text { Acto } \\
\text { IV }\end{array}$} & Celestina & A sí misma & $\begin{array}{l}\text { ¿Qué haré, cuytada, } \\
\text { mezquina de mí? }\end{array}$ & $\begin{array}{l}\text { ¿Que-m faré, trista, } \\
\text { mesquina de mí...? }\end{array}$ \\
\hline & Celestina & Lucrecia & bova & baboya \\
\hline & Alisa & Lucrecia & bova & babau \\
\hline & Alisa & Lucrecia & $\begin{array}{l}\text { ¡Hy, hy, hy! ¡Mala landre } \\
\text { te mate, si de risa puedo } \\
\text { estar...! }\end{array}$ & $\begin{array}{l}\text { ¡Ja! ¡Ja! ¡Ja! Mala pésta } \\
\text { que-t mat, si-m puch star } \\
\text { de riure }\end{array}$ \\
\hline & Celestina & Alisa & $\begin{array}{l}\text { Que maldito sea el diablo } \\
\text { y mi pecado }\end{array}$ & $\begin{array}{l}\text { Que malehit sia lo diable } \\
\text { e lo meu pecat }\end{array}$ \\
\hline & Melibea & Lucrecia & ¿Qué hablas, loca? & ¿Què dius, boja? \\
\hline & Melibea & Celestina & $\begin{array}{l}\text { Desvergonzada barbuda.. } \\
\text { ¡Quemada seas, alcahueta } \\
\text { falsa, hechicera, enemiga } \\
\text { de honestad, causadora } \\
\text { de secretos yerros! } \\
\text {...malvada }\end{array}$ & $\begin{array}{l}\text { Descarada barbuda } \\
\text { ¡Axí-t veges cremada, } \\
\text { falsa alcavota, fatillera, } \\
\text { enemiga d'honestedat, } \\
\text { causadora de segrétes } \\
\text { errades! } \\
\text {...malvada }\end{array}$ \\
\hline & Melibea & $\begin{array}{l}\text { Celestina, } \\
\text { sobre } \\
\text { Calisto }\end{array}$ & dar vida a un loco & donar vida a un boig \\
\hline & Melibea & Celestina & $\begin{array}{l}\text { Vieja maldita } \\
\text { Traydor }\end{array}$ & $\begin{array}{l}\text { Maleyta vélla } \\
\text { Traydora }\end{array}$ \\
\hline & Melibea & $\begin{array}{l}\text { Sobre } \\
\text { Calisto }\end{array}$ & $\begin{array}{l}\text { Loco, saltaparedes, } \\
\text { fantasma de noche, } \\
\text { luengo como cigüeña, } \\
\text { figura de paramento } \\
\text { malpintado; }\end{array}$ & $\begin{array}{l}\text { Boig, cap-de-trons, } \\
\text { fantasma de nits, llarch } \\
\text { com una cigonya, figura } \\
\text { de parament stiragaçada; }\end{array}$ \\
\hline
\end{tabular}




\begin{tabular}{|c|c|c|c|c|}
\hline & Melibea & Celestina & ¿Qué dizes, enemiga? & ¿Què dius, enemiga? \\
\hline & Celestina & Lucrecia & loquilla & bogeta \\
\hline \multirow[t]{9}{*}{ Acto $\mathrm{V}$} & Celestina & Celestina & $\begin{array}{l}\text { ¡O diablo a quién yo } \\
\text { conjuré! }\end{array}$ & $\begin{array}{l}\text { ¡Oh diable, al qual } \\
\text { conjuri! }\end{array}$ \\
\hline & Celestina & Sempronio & loquillo & ximplet \\
\hline & Celestina & Sempronio & bovo & babau \\
\hline & Sempronio & $\begin{array}{l}\text { (Aparte) } \\
\text { Celestina }\end{array}$ & $\begin{array}{l}\text { ¡O lisonjera vieja! } \\
\text { ¡Oh vieja llena de } \\
\text { mal! ¡Oh condiciosa y } \\
\text { avarienta garganta! (...) } \\
\text { Mala medra tiene (...); } \\
\text { Mala vieja, falsa es esta; } \\
\text { Venenosa víbora }\end{array}$ & $\begin{array}{l}\text { ¡Oh falaguera vélla! ¡Oh } \\
\text { vélla plena de mal! ¡Oh } \\
\text { cobejant i avariciosa } \\
\text { góla!(...) Puis fa mala } \\
\text { crexença (...) } \\
\text { ¡Mala vélla falsa és } \\
\text { aquèsta! } \\
\text { Verinósa vibra }\end{array}$ \\
\hline & Celestina & Sempronio & bovo & babau \\
\hline & Celestina & Sempronio & loco & bojot \\
\hline & Calisto & Pármeno & Loco & taboll \\
\hline & Calisto & Pármeno & Desvariado, negligente & ¡Oh desvariejant distrét! \\
\hline & Calisto & Pármeno & $\begin{array}{l}\text { ¡O espacioso Pármeno, } \\
\text { manos de muerto }\end{array}$ & $\begin{array}{l}\text { ¡Oh gansoner Pàrmius, } \\
\text { mans de mort! }\end{array}$ \\
\hline \multirow[t]{9}{*}{$\begin{array}{l}\text { Acto } \\
\text { VI }\end{array}$} & Celestina & Calisto & $\begin{array}{l}\text { Spada mala mate a tus } \\
\text { enemigos y a quien mal } \\
\text { te quiere, }\end{array}$ & $\begin{array}{l}\text { ¡Mala espasa qui mat los } \\
\text { teus enemichs e lo qui- } \\
\text { vol mal! }\end{array}$ \\
\hline & Sempronio & Pármeno & $\begin{array}{l}\text {.te echaré dende con el } \\
\text { diablo! }\end{array}$ & $\begin{array}{l}\text { T'etgegaré d'ací ab lo } \\
\text { diable! }\end{array}$ \\
\hline & Sempronio & Pármeno & $\begin{array}{l}\text { ¡O mal fuego te abrase! } \\
\text { ¡Oh intolerable pestilencia } \\
\text { y mortal te consuma, } \\
\text { rijoso, envidioso, maldito! } \\
\text { ¡Vete de aquí a la mala } \\
\text { ventura! }\end{array}$ & $\begin{array}{l}\text { ¡Oh mal foch qui-t crem! } \\
\text { ¡Oh, que incomportable } \\
\text { pésta e mortal te } \\
\text { consuma, apassionat, } \\
\text { envejós, malehit! ¡Vés- } \\
\text { te'n d'ací en ta mala } \\
\text { ventura! }\end{array}$ \\
\hline & Pármeno & \begin{tabular}{l|} 
Aparte, \\
sobre \\
Calisto \\
\end{tabular} & $\begin{array}{l}\text { Loco } \\
\text { desatinado }\end{array}$ & $\begin{array}{l}\text { Adelerat } \\
\text { Omisión de la frase }\end{array}$ \\
\hline & Sempronio & $\begin{array}{l}\text { A Pármeno, } \\
\text { hablando } \\
\text { de Calisto }\end{array}$ & Maldiziente venenoso & ¡Maldihent verinós! \\
\hline & Celestina & \begin{tabular}{l|} 
Calisto \\
(sobre ella \\
misma)
\end{tabular} & $\begin{array}{l}\text { Llamándome [Melibea] } \\
\text { hechizera, alcahueta, } \\
\text { vieja falsa, barvuda, } \\
\text { malhechora }\end{array}$ & $\begin{array}{l}\text { Dient-me fetillera, } \\
\text { alcavota, vélla falsa } \\
\text { e molts altres noms } \\
\text { ignominiosos }\end{array}$ \\
\hline & Calisto & $\begin{array}{l}\text { A Pármeno } \\
\text { y a sí } \\
\text { mismo }\end{array}$ & $\begin{array}{l}\text { Moços adevinos, } \\
\text { reçongadores, enemigos } \\
\text { de mi bien. } \\
\text { Vellaco, embidioso }\end{array}$ & $\begin{array}{l}\text { Minyons endevinayres, } \\
\text { sornaguers, enemichs del } \\
\text { meu bé. } \\
\text { Bricó, envejós }\end{array}$ \\
\hline & Calisto & Celestina & O mezquino de mí & ¡Oh pobre de mi! \\
\hline & Calisto & Sempronio & $\begin{array}{l}\text { Loco, desvariado, } \\
\text { atajasolazes }\end{array}$ & $\begin{array}{l}\text { Foll, desvariejant, trenca- } \\
\text { deports }\end{array}$ \\
\hline
\end{tabular}




\begin{tabular}{|c|c|c|c|c|}
\hline & Pármeno & $\begin{array}{l}\text { Sempronio } \\
\text { (sobre } \\
\text { Calisto) } \\
\end{array}$ & Tan loco hombre nascido & Tan trastocat home nat \\
\hline \multirow[t]{13}{*}{$\begin{array}{c}\text { Acto } \\
\text { VII }\end{array}$} & Celestina & Pármeno & $\begin{array}{l}\text { ¿Qué dirás, loquillo, a } \\
\text { todo esto? }\end{array}$ & $\begin{array}{l}\text { ¿Què-y diras, boget, a tot } \\
\text { açò? }\end{array}$ \\
\hline & Celestina & $\begin{array}{l}\text { Pármeno } \\
\text { (aparte) }\end{array}$ & $\begin{array}{l}\text { Lastimásteme, don } \\
\text { loquillo }\end{array}$ & $\begin{array}{l}\text { M'has tocat al viu, en } \\
\text { boget. }\end{array}$ \\
\hline & Celestina & Pármeno & ¡Calla, bovo! & ¡Calla, ximplet! \\
\hline & Areúsa & Celestina & $\begin{array}{l}\text { ¡Válala el diablo a esta } \\
\text { vieja! }\end{array}$ & $\begin{array}{l}\text { ¡Valga-li lo diable a } \\
\text { aquexa vélla! }\end{array}$ \\
\hline & Areúsa & Celestina & $\begin{array}{l}\text { Mal gozo vea de mi, si } \\
\text { burlo }\end{array}$ & $\begin{array}{l}\text { Mala fí jo faça, si-m burle } \\
\text { de tu }\end{array}$ \\
\hline & Celestina & Areúsa & No te hagas bova & No faces lo desentès \\
\hline & Areúsa & Celestina & $\begin{array}{l}\text { Mala landre me mate si te } \\
\text { entendía }\end{array}$ & $\begin{array}{l}\text { Que-m cayga ací morta, si } \\
\text { t'entenia }\end{array}$ \\
\hline & Areúsa & Celestina & $\begin{array}{l}\text { Landre me mate, que me } \\
\text { fino de empacho }\end{array}$ & ¡Ja-m fira un llamp \\
\hline & Celestina & Areúsa & Llégate acá, asno & Fés-te ençà, tros d'ase \\
\hline & Celestina & Pármeno & $\begin{array}{l}\text { don ruyn }(. . .) \\
\text { Negligente, vergonçoso }\end{array}$ & $\begin{array}{l}\text { En malvat(...) } \\
\text { Negligent, vergonyós }\end{array}$ \\
\hline & Celestina & $\begin{array}{l}\text { Areúsa- } \\
\text { hablando } \\
\text { de } \\
\text { Pármeno }\end{array}$ & $\begin{array}{l}\text { Putillo, gallillo, } \\
\text { barviponiente }\end{array}$ & $\begin{array}{l}\text { Bardaxó, gallet, } \\
\text { barbamech }\end{array}$ \\
\hline & Celestina & Areúsa & $\begin{array}{l}\text { Me haces a mí necia y } \\
\text { vergonzosa }\end{array}$ & $\begin{array}{l}\text { Omisión de } 3 \text { párrafos } \\
\text { (interpolaciones) del } \\
\text { traductor }\end{array}$ \\
\hline & Elicia & Celestina & Desacordada eres, cierto & $\begin{array}{l}\text { Desmemoriada ets, per } \\
\text { cert }\end{array}$ \\
\hline \multirow{6}{*}{$\begin{array}{c}\text { Acto } \\
\text { VIII }\end{array}$} & Sempronio & Pármeno & ¿Qué es esto, desvariado? & ¿Què és axò, forassenyat? \\
\hline & Sempronio & Pármeno & bovo & bajanaç \\
\hline & Sempronio & $\begin{array}{l}\text { A Pármeno, } \\
\text { hablando } \\
\text { de Calisto }\end{array}$ & $¡ O$ hydeputa, el trobador! & $\begin{array}{l}\text { ¡Oh fill de puta, e quin } \\
\text { trobayre! }\end{array}$ \\
\hline & Calisto & Pármeno & ¿Qué dizes, loco? & ¿Què dius boig? \\
\hline & Calisto & Pármeno & desvariado & Cap-de-trons \\
\hline & Pármeno & $\begin{array}{l}\text { Calisto } \\
\text { (aparte) }\end{array}$ & $\begin{array}{l}\text { ¡Allá irás con el diablo } \\
\text { tú y malos años! ¡Y en } \\
\text { tal hora comieses el } \\
\text { diacitrón, como Apuleyo } \\
\text { el veneno, que le } \\
\text { convirtió en asno! }\end{array}$ & $\begin{array}{l}\text { ¡Allà aniras ab lo diable, } \\
\text { en ton mal any, e en tal } \\
\text { hora haguesses menjat lo } \\
\text { poncèm, com Apulèyus lo } \\
\text { verí qui-l convertí en ase! }\end{array}$ \\
\hline \multirow[t]{3}{*}{$\begin{array}{l}\text { Acto } \\
\text { IX }\end{array}$} & Celestina & $\begin{array}{l}\text { Areúsa, } \\
\text { Elicia }\end{array}$ & $\begin{array}{l}\text { ¡Mochachas; } \\
\text { mochachas;bovas! }\end{array}$ & ¡Xicotes! ¡baboyes! \\
\hline & Elicia & Sempronio & $\begin{array}{l}\text { ¡Apártateme allá, } \\
\text { desabrido, enojoso! } \\
\text { ¡Mal me haga Dios! }\end{array}$ & $\begin{array}{l}\text { ¡Fés-te enllà, dessaborit, } \\
\text { enujós! } \\
\text { ¡Que Déu me castich! }\end{array}$ \\
\hline & Elicia & Sempronio & malvado & malvat \\
\hline
\end{tabular}




\begin{tabular}{|c|c|c|c|c|}
\hline & Areúsa & $\begin{array}{l}\text { Elicia, } \\
\text { hablando } \\
\text { de los } \\
\text { criados }\end{array}$ & Locos porfiado & Fólls perfidióse \\
\hline & Elicia & Sempronio & $\begin{array}{l}\text { ¡De mala cançre sea } \\
\text { comida esa boca } \\
\text { desgraciada, enojoso! }\end{array}$ & $\begin{array}{l}\text { ¡De mal cranch sia } \\
\text { menjada aqueixa } \\
\text { desgayrada e enujósa } \\
\text { bóca! }\end{array}$ \\
\hline & Celestina & $\begin{array}{l}\text { Sempronio, } \\
\text { Pármeno, } \\
\text { Elicia, } \\
\text { Areúsa }\end{array}$ & $\begin{array}{l}\text { Putillos, loquillos, } \\
\text { traviesos }\end{array}$ & $\begin{array}{l}\text { Putarrons, bogets, } \\
\text { entremaliats }\end{array}$ \\
\hline & Areúsa & $\begin{array}{l}\text { Celestina } \\
\text { (sobre } \\
\text { jóvenes } \\
\text { ricas a sus } \\
\text { criadas) }\end{array}$ & $\begin{array}{l}\text { Ladrona, puta; tiñosa, } \\
\text { bellaca, golosa, puerca; } \\
\text { çuzia, necia, desaliñada, } \\
\text { ladrona; mala mujer }\end{array}$ & $\begin{array}{l}\text { Lladrona, putana;tinyosa, } \\
\text { briçona, goluda, porca, } \\
\text { xarxota, barrohera, } \\
\text { dexada; mala fembra }\end{array}$ \\
\hline & Lucrecia & $\begin{array}{l}\text { Celestina } \\
\text { (aparte) }\end{array}$ & $\begin{array}{l}\text { ¡Así te arrastren, traydora! } \\
\text { Vieja falsa }\end{array}$ & $\begin{array}{l}\text { ¡Axí-t roceguen, traydora! } \\
\text { Vélla falsaria }\end{array}$ \\
\hline \multirow[t]{4}{*}{ Acto $\mathrm{X}$} & Celestina & $\begin{array}{l}\text { Melibea } \\
\text { (aparte) }\end{array}$ & Doña loca & $\mathrm{Na}$ fólla \\
\hline & Melibea & Celestina & $\begin{array}{l}¡ O \text { por Dios, que me } \\
\text { matas! }\end{array}$ & $\begin{array}{l}\text { ¡Oh, Déu méu, com me } \\
\text { mates! }\end{array}$ \\
\hline & Melibea & Celestina & ¡Ay, mezquina de mí! & ¡Ay pobre de mí! \\
\hline & Celestina & Melibea & ¡Oh, mezquina yo! & ¡Oh pobre de mí! \\
\hline \multirow[t]{2}{*}{$\begin{array}{l}\text { Acto } \\
\mathrm{XI}\end{array}$} & Calisto & $\begin{array}{l}\text { Sempronio } \\
\text { y Pármeno }\end{array}$ & $\begin{array}{l}\text { Locos, vellacos, } \\
\text { sospechosos }\end{array}$ & $\begin{array}{l}\text { Boigs, bergants, } \\
\text { scarafallóses }\end{array}$ \\
\hline & Sempronio & Pármeno & Puta alcahueta & Puta alcavota \\
\hline \multirow[t]{9}{*}{$\begin{array}{c}\text { Acto } \\
\text { XII }\end{array}$} & Calisto & Sempronio & desatinado & exelebrat \\
\hline & Pármeno & Sempronio & El necio de nuestro amo & lo taboll del senyor \\
\hline & Melibea & Lucrecia & loca & boja \\
\hline & Calisto & Melibea & $\begin{array}{l}\text { ¡O engañosa mujer, } \\
\text { Celestina! } \mathrm{O} \text { enemiga }\end{array}$ & $\begin{array}{l}\text { ¡Oh enganyósa fémbra } \\
\text { Celestina! }\end{array}$ \\
\hline & Celestina & $\begin{array}{l}\text { Sempronio } \\
\text { y Pármeno }\end{array}$ & ¡O locos, traviesos! & ¡Oh fólls entremaliats! \\
\hline & Celestina & $\begin{array}{l}\text { Sempronio } \\
\text { y Pármeno }\end{array}$ & $\begin{array}{l}\text { Landre me mate si no me } \\
\text { espanto en verte tan fier }\end{array}$ & Que de glànola muyra \\
\hline & Celestina & $\begin{array}{l}\text { Sempronio } \\
\text { y Pármeno }\end{array}$ & ¡Gracioso es el asno! & !Mirau lo troç- d'ase! \\
\hline & Celestina & $\begin{array}{l}\text { Sempronio } \\
\text { y Pármeno, } \\
\text { hablando } \\
\text { de Elicia }\end{array}$ & loca & boja \\
\hline & Celestina & Sempronio & Calla tu lengua & Aguanta't la llengua \\
\hline
\end{tabular}




\begin{tabular}{|c|c|c|c|c|}
\hline & Pármeno & Celestina & No me hinches las narizes & $\begin{array}{l}\text { No-m faces pujar la } \\
\text { mosca al nas }\end{array}$ \\
\hline & Sempronio & Celestina & $\begin{array}{l}\text { O vieja avarienta, } \\
\text { garganta muerta de sed } \\
\text { por dinero! }\end{array}$ & $\begin{array}{l}\text { ¡Oh vélla avariciósa, góla } \\
\text { morta de set per diners! }\end{array}$ \\
\hline & Celestina & $\begin{array}{l}\text { Sempronio } \\
\text { y Pármeno }\end{array}$ & rufiane & rufian \\
\hline & Sempronio & Celestina & $\begin{array}{l}\text { Doña hechizera, que yo } \\
\text { te haré ir al infierno con } \\
\text { cartas }\end{array}$ & $\begin{array}{l}\text { Na fatillera, quét faré } \\
\text { anar ab cartes al infern }\end{array}$ \\
\hline & Elicia & $\begin{array}{l}\text { Sempronio } \\
\text { y Pármeno }\end{array}$ & $\begin{array}{l}\text { O crueles enemigos, en } \\
\text { mal poder os veáys }\end{array}$ & $\begin{array}{l}\text { ¡Oh cruels enemichs! ¡En } \\
\text { mal poder de justicia us } \\
\text { vejau! }\end{array}$ \\
\hline $\begin{array}{l}\text { Acto } \\
\text { XIV }\end{array}$ & Sosia & Aparte & el bovo de Calisto & lo babau de Calist \\
\hline \multirow[t]{2}{*}{$\begin{array}{l}\text { Acto } \\
\text { XIX } \\
(\mathrm{xV} \text { en } \\
\text { Bul. })\end{array}$} & Lucrecia & Aparte & $\begin{array}{l}\text { Mala landre me mate si } \\
\text { mas lo escucho }\end{array}$ & $\begin{array}{l}\text { Mala bua m'atuhesca, si } \\
\text { més jo-ls pare orèlla }\end{array}$ \\
\hline & Sosia & Traso & Vellacos, rufiane & Omisión del traductor \\
\hline $\begin{array}{l}\text { Acto } \\
\text { XXI } \\
\text { (xVI en } \\
\text { Bul.) }\end{array}$ & Pleberio & Alisa & $\begin{array}{l}\text { falsa alcahueta } \\
\text { Enemigo de amigos, } \\
\text { amigo de enemigos } \\
\text { [Amor] }\end{array}$ & $\begin{array}{l}\text { falsa alcavota } \\
\text { Enemich d'amichs, amich } \\
\text { d'enemichs [Amor] }\end{array}$ \\
\hline
\end{tabular}




\section{Ugarte Ballester, Xus, «Ensayo de descalificaciones y maldiciones personales en Celestina y en la traducción catalana de Antoni Bulbena», Celestinesca 35 (2011), pp. 137-158.}

\section{RESUMEN}

El propósito de este artículo es doble: por una parte, realizar un vaciado exhaustivo de los adjetivos calificativos que menosprecian o atacan al adversario, así como de las frases en general exclamativas, que expresan malos deseos y se profieren con tono amenazador; por otra, cotejar este corpus con el vaciado también completo de la traducción catalana de Celestina (Antoni Bulbena Tosell, 1914), comentando al mismo tiempo las opciones traductológicas del trujamán: léxico, fraseología, arcaísmos, registro, etc.

Palabras Clave: Traducción catalana de Celestina, Antoni Bulbena, descalificaci nes, maldiciones personales.

\section{ABSTRACT}

The aim of this article is twofold: first, to compile an exhaustive list of qualifying adjectives used to disparage or attack an adversary, as well as generally exclamatory phrases conveying evil wishes and uttered in threatening tones; second, to compare this corpus with the complete compilation of the Catalan translation of Celestina (Antoni Bulbena Tosell, 1914), while commenting on the translator's choices involving lexis, phraseology, archaisms, register, and so on.

KEY WORDS: Catalan translation of Celestina, Antoni Bulbena, disparaging language, personal curses.

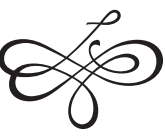

